\title{
Kajian Fintech dalam Konsep Behaviouristik
}

\author{
Lilik Nurcholidah', Mugi Harsono \\ ${ }^{1}$ Universitas Islam Lamongan, Indonesia \\ ${ }^{2}$ Universitas Sebelas Maret, Surakarta, Indonesia
}

Email corresponding author: liliknurcholidah12@gmail.com/mugiharsono_fe@staf.uns.ac.id

\begin{abstract}
ABSTRAK
Teknologi dihasilkan dari perkembangan ilmu pengetahuan yang diimplementasikan pada masyarakat. Financial Technology berupaya untuk memudahkan manusia dalam memenuhi kebutuhan yang terus meningkat, mobilisasi manusia yang semakin cepat, serta kesibukan manusia yang selalu bertambah. Perkembangan technology merupakan sesuatu yang kritis. Dalam teori behaviouristik mengamati perubahan tingkah laku dan perbuatan yang berdasarkan kenyataan. Artikel ini membahas bagaimana keselarasan antara adanya financial Technologi disandingkan dengan perubahan karateristik behavior masyarakat dalam perilak, sikap dan pola hidup. Teori behavioristik adalah teori yang menekankan pada tingkah laku manusia sebagai akibat dari interaksi antara stimulus dan respon. Teori Behavior yang dihubungkan dengan Fintech adalah Teori Kognitif, Teori Afektif dan Behaviour Intentions.
\end{abstract}

Kata Kunci: Fintech, cognitive element, affective elements, behavioral intentions

\section{PENDAHULUAN}

Technologi Informasi dalam dunia keuangan bukanlah suatu hal yang baru, terkadang bukanlah suatu hal baru, terkadang terdapat suatu layanan yang terkendala dengan biaya, kebiasaan pengguna, serta kandungan resiko sehingga beberapa layanan keuangan berbasis teknologi informasi menunggu kesiapan dari berbagai segi sehingga siap untuk dimanfaatkan secara optimal. Di era serba teknologi seperti saat ini, sudah banyak startup baru yang dibangun, khsususnya pada bidang fintech . Fintech adalah kepanjangan dari financial technology. Pada intinya, fintech adalah salah satu perusahaan yang bergerak dalam jasa keuangan yang sudah dikombinasikan dengan teknologi.

Tahun 2019 adalah tahun dimana segala aspek dalam kehidupan manusia telah tersentuh oleh teknologi. Kebutuhan yang meningkat, mobilisasi manusia yang semakin cepat, serta kesibukan manusia yang selalu bertambah memaksa adanya fasilitas yang dapat memenuhi itu semua. Dengan mempertimbangkan cepat berkembangnya teknologi di Indonesia, tidak mustahil bila semua dapat diwujudkan. Konsep financial Technology dapat memudahkan apa yang dirasa sulit dan memakan banyak waktu, namun yang harus diperhatikan adalah apakah masuknya era fintech kedalam bisnis sesuai dengan budaya masyarakat Indonesia yang terkenal dengan masyarakat social

Berdasarkan Pribadiono, Hukum, Esa, \& Barat (2016), Financial Technology (FinTech) merupakan perpaduan antara teknologi dan fitur keuangan atau dapat juga diartikan inovasi pada sektor finansial dengan sentuhan teknologi moderen. Berdasarkan Dorfleitner, Hornuf, Schmitt, \& Weber (2017), FinTech merupakan industri yang bergerak dengan sangat cepat dan dinamis dimana terdapat banyak model bisnis yang berbeda. Berdasarkan Hsueh (2017), Teknologi Keuangan juga disebut sebagai FinTech, merupakan model layanan keuangan baru yang dikembangkan melalui inovasi teknologi informasi. Maka menurut penulis, Financial Technology adalah layanan yang menggabungkan teknologi dan keuangan dimana layanan ini menyediakan inovasi pada bisnis. 
Tipe-tipe Financial Technology (Fintech) Menurut Hsueh (2017), Terdapat tiga tipe financial technology yaitu : Sistem pembayaran melalui pihak ketiga (Third-party payment systems) Contoh - contoh sistem pembayaran melalui pihak ketiga yaitu crossborder EC, online-to-offline $(\mathrm{O} 2 \mathrm{O})$, sistem pembayaran mobile, dan platform pembayaran yang menyediakan jasa seperti pembayaran bank dan transfer. Kedua, Peer-to-Peer (P2P) Lending Peer-to-Peer Lending merupakan platform yang mempertemukan pemberi pinjaman dan peminjam melalui internet. Peer-to-Peer Lending menyediakan mekanisme kredit dan manajemen risiko. Platform ini membantu pemberi pinjaman dan peminjam memenuhi kebutuhan masing-masing dan menghasilkan penggunaan uang secara efisien. Ketiga Crowdfunding Crowdfunding merupakan tipe FinTech di mana sebuah konsep atau produk seperti desain, program, konten, dan karya kreatif dipublikasikan secara umum dan bagi masyarakat yang tertarik dan ingin mendukung konsep atau produk tersebut dapat memberikan dukungan secara finansial. Crowdfunding dapat digunakan untuk mengurangi kebutuhan finansial kewirausahaan, dan memprediksi permintaan pasar.

Manfaat Financial Technology (FinTech) Menurut Bank Indonesia, Perkembangan Fintech yang sangat pesat di Indonesia dapat membawa banyak manfaat, manfaat tersebut dapat bagi peminjam, investor maupun perbankan di Indonesia : Bagi peminjam, manfaat yang dapat dirasakan seperti mendorong inklusi keuangan, memberikan alternatif pinjaman bagi debitur yang belum layak kredit, prosesnya mudah dan cepat, dan persaingan yang ditimbulkan mendorong penurunan suku bunga pinjaman. Bagi investor FinTech, manfaat yang dapat dirasakan seperti alternatif investasi dengan return yang lebih tinggi dengan risiko default yang tersebar di banyak investor dengan nominal masing - masing cukup rendah dan investor dapat memilih peminjam yang didanai sesuai preferensinya. Bagi perbankan, kerjasama dengan FinTech dapat mengurangi biaya seperti penggunaan non-traditional credit scoring untuk filtering awal aplikasi kredit, menambah Dana Pihak Ketiga (DPK), menambah channel penyaluran kredit dan merupakan alternatif investasi bagi perbankan. Menurut Otoritas Jasa Keuangan (2016), manfaat FinTech di Indonesia, yaitu:

1. Mendorong distribusi pembiayaan Nasional masih belum merata di 17.000 pulau

2. Mendorong kemampuan ekspor UMKM yang saat ini masih rendah

3. Meningkatkan Inklusi keuangan nasional

4. Mendorong pemerataan tingkat kesejahteraan penduduk

5. Membantu pemenuhan kebutuhan pembiayaan dalam negeri yang masih sangat besar.

Perilaku adalah tindakan atau aktivitas dari manusia itu sendiri yang mempunyai bentangan yang sangat luas antara lain: berjalan, berbicara, menangis, tertawa, bekerja, kuliah, menulis, membaca, dan sebagainya. Dari uraian ini dapat disimpulkan bahwa yang dimaksud perilaku manusia adalah semua kegiatan atau aktivitas manusia, baik yang diamati langsung, maupun yang tidak dapat diamati oleh pihak luar (Notoatmodjo2003: 114). Pendekatan behavioral berpijak pada anggapan bahwa kepribadian manusia adalah hasil bentukan dari lingkungan tempat ia berada. Dengan anggapan ini, pendekatan behavioral mengabaikan faktor pembawaan manusia yang dibawa sejak lahir, seperti perasaan, insting, kecerdasan, bakat, dan lain-lain. Manusia dianggap sebagai produk lingkungan sehingga manusia menjadi jahat, beriman, penurut, berpandangan kolot, serta ekstrem sebagai bentukan lingkungannya. (Endraswara2008 :56-57).

Penguat positif adalah rangsangan yang memperkuat atau mendorong suatu tindak balas. Sedangkan penguatan negatif ialah penguatan yang mendorong individu untuk menghindari suatu tindakan balas tertentu yang tidak memuaskan.8 Penguat harus berdekatan dengan respon seseorang, yaitu penguat seharusnya terjadi ketika respon yang diinginkan telah terjadi. Teori ini lebih menitikberatkan pada tingkah laku aktor dan lingkungan. Dalam Behaviorisme Skinner, pikiran sadar atau tidak sadar tidak diperlukan untuk menjelaskan 
perilaku dan perkembangan. Oleh karena itu para Behvioris yakin bahwa perkembangan dipelajari dan sering berubah sesuai dengan pengalaman-pengalaman lingkungan. Pendekatan behavior bertujuan untuk menghilangkan tingkah laku yang salah dan membentuk tingkah laku baru. Pendekatan tingkah laku dapat digunakan dalam menyembuhkan berbagai gangguan tingkah laku dari yang sederhana hingga yang kompleks, baik individual maupun kelompok.

\section{Cognitive Element of Fintech}

Teori kognitif oleh Greenwald (1968) dan Petty, Ostrom \& Brack (1981) dalam Baron \& Byme (1991) mensentralkan perhatiannya pada analisis respons kognitif, dimana: "Suatu usaha untuk memahami apa yang difikirkan orang sewaktu mereka dihadapkan pada stimulus persuasive, dan bagaimana pikiran serta proses kognitif menetukan apakah mereka mengalami perubahan sikap \& sejauhmana perubahan itu terjadi" (Azwar, 1997:18). Teori kognitif meliputi kegiatan mental, seperti berfikir, mengetahui, memahami, dan dan kegiatan konsepsi mental seperti: sikap, kepercayaan, dan pengharapan, kemudian itu merupakan faktor yang menentukan di dalam perilaku. Di dalam teori kognitif ini terdapat suatu interes yang kuat dalam jawaban (response) atas akibat dari perilaku yang tertutup.

Fintech memerlukan cara pemikiran dalam penerimaannya, salah satu indicator utama adalah "Trust". Menurut Robbins dan Judge (2008), Kepercayaan adalah suatu harapan positif bahwa orang lain tidak akan bertindak secara oportunistik. Istilah oportunistik merujuk pada risiko di dalam hubungan berbasis kepercayaan. Dalam kajian psikologi, Rotter mengatakan trust diartikan sebagai suatu kecenderungan seseorang untuk yakin pada orang lain (dalam Mckinght dkk, 2002: 336). Sementara Yamagisi(1998) menjelaskan trust adalah keyakinan orang kepada maksud baik orang lain yang tidak merugikan mereka, peduli pada hak mereka, dan melakukan kewajibannya. Dalam pemberian Stimulus mengenai Fintech pada Masyarakat, tentunya sebagai media harus bisa memberikan suatu kepercayaan dan dampak positif terhadap respon yang nantinya akan diberikan. Sebab dalam respon yang diterima nantinya akan berbeda apabila stimulusnya tidak memberikan trust yang baik. Maka dengan meyakinkan bahwa Fintech itu aman dan legal serta dapat di gunakan dimana saja tanpa ada rasa kekhawatiran, respon yang baik akan diberikan kepada masyarakat.

Indikator Kedua adalah "Fintech category Involvment" sebagai motivasi untuk memproses informasi. Celsi dan Olson (1988) seperti dikutip Japarianto dan Sugiharto (2013) menyatakan bahwa selama keterlibatan konsumen tinggi, konsumen akan memperhatikan informasi yang berhubungan dengan produk tersebut, memberikan lebih banyak upaya untuk memahami produk tersebut dan memfokuskan perhatian pada informasi produk yang terkait didalamnya.

Para penelitian telah mendefinisikan keterlibatan dari berbagai macam sudut pandanya. O'Cass (2005) seperti dikutip Japarianto dan Sugiharto (2013) mendefinisikan keterlibatan sebagai niat atau bagian motivasional yang ditimbulkan oleh stimulus atau situasi tertentu, dan ditujukan melalui ciri penampilan. Zaichkowsky (1985) seperti dikutip Japarianto dan Sugiharto (2013) mendefinisikan keterlibatan sebagai hubungan seseorang terhadap sebuah objek berdasarkan kebutuhan, nilai, dan ketertarikan. Mowen dan Minor (2010) mendefinisikan keterlibatan sebagai sebagai pribadi yang dirasakan penting dan atau keinginan konsumen terhadap disposisi barang, ide, jasa, perolehan, dan konsumsi.

Untuk memotivasi Fintech dalam masyarakat dibutuhkan ketepatan informasi, dan selalu melibatkan Fintech dalam transaksi apapun. Selama informasi yang diterima tentang Fintech adalah informasi yang baik dan kemudahan yang diperoleh cepat dalam bertransaksi, tidak menutup kemungkinan Fintech menjadi sesuatu yang penting sebagai kebutuhan masyarakat.

Pada indicator selanjutnya, "Cultural-Ethnic", Robert Dubin (1996) dalam Liliweri (2011:87) memperkenalkan sebuah teori baru yaitu teori adaptasi budaya di mana teori ini 
meramalkan bahwa setiap proses adaptasi akan menghasilkan sikap individu untuk menyerahkan diri kepada partisipan lain atas dasar keyakinan budaya bersama. Hal ini menggambarkan Fintech sebagai pendatang baru yang butuh penyesuaian diri terhadap normanorma dan nilai yang berlaku di maayarakat agar bisa dengan mudah diterima.

\section{Affective Elements of Fintech}

Menurut David R. Krathwohl, mendefinisikan ranah afektif Affective, objectives which emphasize a feeling tone, an emotion, or degree of acceptance or rejection. Afektif ialah perilaku yang menekankan perasaan, emosi, atau derajat tingkat penolakan atau penerimaan terhadap suatu objek. Gerungan (2004: 160) juga menguraikan pengertian sikap atau attitude sebagai suatu reaksi pandangan atau perasaan seorang individu terhadap objek tertentu. Dalam kaitannya, bagaimana sikap yang diberikan masyarakat terhadap adanya Fintech, apakah masyarakat menerima dengan baik (positive Affect) atau mereka menolak dengan adanya Fintech (negative Affect). Jika masyarakat memiliki pandangan baik, mungkin mereka akan menggunakan Fintech pada hal-hal yang positif tetapi jika mereka memiliki pandangan buruk, untuk mendowload aplikasi layanan Fintech saja tidak akan mau, apalagi meenggunakannya.

Sikap terbuka dan sikap tertutup akan di tunjukkan oleh masyarakat dalam berdaptasi dengan adanya Fintech memang beragam. Dalam hal ini perlu pendekatan atau sosialisasi tentang Finteh kepada masyarakat secara mendalam dan tepat sasaran agar masyarakat bisa cepat beradaptasi dengan Fintech. Penelitian terbaru menemukan konsep affective ada 3 yakni : life satisfaction, positive affect, dan negative affect. Positive affect adalah frekuensi dan intensitas emosi yang menyenangkan. Negative Affect adalah frekuensi dan intensitas emosi yang tidak menyenangkan. Kedua Affect tersebut adalah perasaan orang terhadap kehidupan mereka (Andrews dan Robinson, 1992 ; Argyle, 2001; Diener ; 2000; Diener.,dkk 1999 dalam Baumgardner, 2010).

Penelitian ini mengacu kepada penelitian lain sebelumnya yang menemukan hubungan antara perilaku afektif dan kinerja individu (Chen \& Spector, 1992), indikator ketegangan dalam lingkungan kerja (Moyle, 1995) dan prediktor yang berkaitan dengan kinerja karyawan (Elsbach \& Barr, 1999). Keadaan emosional tersebut telah diukur sebagai positive affectivity dan negative affectivity dengan menggunakan metode yang dikembangkan oleh Watso, Clark, dan Tellegen (1988). Teoritis dan temuan empiris tentang hubungan perilaku berasal dari teori tindakan yaitu perasaan positif atau negatif dari individu dalam hal berperilaku (Fishbein \& Ajzen, 1975, hlm . 216).

Perasaan positif seperti senang, gembira dan puas dengan adanya Fintech akan ditimbulkan oleh masyarakat. Tetapi jika masyarakat sudah merasa tertutup dan tidak tertarik dengan Fintech maka hal itu disebut perasaan negative.

\section{Fintech Sebagai Behavioral Intentions}

Dharmmesta (2008) mendefinisikan bahwa behavioral intention merupakam suatu perilaku atau sikap konsumen yang memiliki keinginan untuk menggunakan jasa secara terus menerus. Apabila suatu produk mempunya behavioural intention yang menguntungkan maka perusahaan tersebut akan dapat bertahan dan memenangkan persaingan.

Dari beberapa pendapat tentang behavioural intention maka dapat disimpulkan bahwa variabel behavioural intention merupakan tujuan akhir. Apabila suatu produk mempunya behavioural intention yang menguntungkan maka perusahaan tersebut akan dapat bertahan dan memenangkan persaingan. Salah satu dari behavioural intention yang menguntungkan adalah adanya sikap posistif tentang suatu produk atau penyedia jasa. Sikap positif ini dapat berupa word of mouth yang posistif. word of mouth ini meruapakan promosi yang berbiaya murah dan memepunyai efek yang luar biasa terhadap kelangsungan hidup perusahaan. Apabila konsumen kita menyebarkan berita bagus kepada orang alain atau teman -teman nya makan akan 
mendorong terjadinya pembelian. Behavioural intention yang posistif juga mempunyai manfaat yang banyak perusahaan. Salah satunya adalah konsumen menjadi loyal terhadap produk atau jasa yang digunakan. Loyalitas merupakan hal yang menjadi tujuan dari perusahaan akan produk atau jasa. Banyak sekali perusahaan menggunakan segala cara agar konsumen menjadi loyal terhadap brand atau produk mereka.

Dalam kaitannya dengan layanan Fintech, behavioural intention adalah bentuk sikap positif yang ditunjukkan masyarakat. Dengan adanya layanan Fintech berarti masyarakat merasa terbantu dan beruntung. Banyak sekali manfaat yang didapatkan dengan menggunakan layanan Fintech.

Customer satisfaction memiliki hubungan positif terhadap attitude towards the website (Carlson dan O'Cass., 2010). Kepuasaan dari konsumen dan perilaku/sikap konsumen menunjukkan peningkatan dalam kepuasaan konsumen terhadap atribut sebuah situs berhubungan dengan pembentukan perilaku positif terhadap situs tersebut. Ketika kepuasaan konsumen diperhitungkan sebagai after-service, maka tingkat kepuasaan konsumen akan terbentuk sebagai hasil dari kepuasan-kepuasan kosumen setiap kali menggunakan jasa.

Jika masyarakat merasa puas menggunakan Fintech, maka terjadi hubungan positif dan reaksi baik yang diberikan oleh masyarakat dengan adanya layanan Fintech.

\section{KESIMPULAN}

Fintech dalam konsep behaviouristik menggambarkan bahwa fintech bisa dilihat dari 3 aspek yakni : kognitif element, afektif element dan behavioral intention. Jadi reaksi masyarakat terhadap Fintech bisa ditunjukkan dari cara berfikir yang terdiri dari kepercayaan akan Fintech, Sebab dalam respon yang diterima nantinya akan berbeda apabila stimulusnya tidak memberikan trust yang baik. Maka dengan meyakinkan bahwa Fintech itu aman dan legal serta dapat di gunakan dimana saja tanpa ada rasa kekhawatiran, respon yang baik akan diberikan kepada masyarakat. Lalu Fintech menjadi prodak kategori Involvement, bahwa Untuk memotivasi Fintech dalam masyarakat dibutuhkan ketepatan informasi, dan selalu melibatkan Fintech dalam transaksi apapun. Kemudian melihat budaya, dengan. menggambarkan Fintech sebagai pendatang baru yang butuh penyesuaian diri terhadap norma-norma dan nilai yang berlaku di maayarakat agar bisa dengan mudah diterima. Selanjutnya melihat Fintech dari sikap, yakni sikap positif dan sikap negative. Jika sikap positif yang ditimbulkan maka behavioral intention akan diterima dengan baik, dengan kata lain Fintech menjadi hal yang memuaskan bagi masyarakat.

\section{DAFTAR PUSTAKA}

Carlson, J \& Aron O’Cass, A. (2010). “Exploring the relationshipd between e-service quality, satisfaction, attitudes and behaviours in contentdriven e-service web sites". Journal of service marketing, Vol. 24 No. 2, pp. 112-127.

Elliot, et.al, Educational Psychology: Effective Teaching, Effective learning, The Mc. Graw Hill Companies, America, 2000.

Gandasetiawan, Ratih Zimmer, Mengoptimalkan IQ \& EQ Anak Melalui Metode Sensomotorik, Penerbit Libri, Jakarta, 2010.

Gredler, Margaret E. Bell, Belajar dan Membelajarkan, Terj. Munandir, Rajawali, Jakarta, Ed. 1, Cet. 1, 1991.

Hasan, Aliah B. Purwakania, Psikologi Perkembangan Islami: Menyingkap Rentang Kehidupan Manusia dari Prakelahiran hingga Pascakematian, PT. Raja Grafindo Persada, Jakarta, 2006 
Mussen, Paul Henry, Perkembangan dan Kepribadian Anak, Terj. Meitasari Tjandrasa, Erlangga, Jakarta, Ed.6, 1996.

Papalia, Diane E., et. al., Human Development (Psikologi Perkembangan), Terj. A. K. Anwar, Kencana, Jakarta, Ed. 9, 2008.

Piaget, Jean, \& Barbel Inhelder, Psikologi Anak, Terj. Miftahul Jannah, Pustaka Pelajar, Yogyakarta, Cet. 1, 2010.

Piaget, Jean, Antara Tindakan Dan Pikiran, disunting oleh Agus Cremers, PT. Gramedia, Jakarta, 1988.

Romlah, Psikologi Perkembangan, Universitas Muhammadiyah Malang Press, Malang, 2010.

Syairozi, M. I., Pambudy, A. P., \& Yaskun, M. (2021). Analisis Penerapan Good Governance dalam Sistem Informasi Keuangan Daerah. Prosiding Penelitian Pendidikan dan Pengabdian 2021, 1(1), 49-59.

Syairozi, M. I. (2011). Analisis peranan sektor pertanian terhadap produk domestik regional bruto (PDRB) di kabupaten Malang (periode 2000-2008) (Doctoral dissertation, Universitas Negeri Malang).

Santrock, John W., Psikologi Pendidikan, Terj. Tri Wibowo B.S., Kencana, Jakarta, Ed. 2, 2007.

Satiadarma, Monty P., \& Fidelis E. Waruwu, Mendidik Kecerdasan. Pedoman bagi orang tua dan guru dalam mendidik anak cerdas, Media Grafika, Jakarta, 2003.

Liliweri, Alo. 2002. Makna Budaya dalam Komunikasi Antarbudaya. Yogyakarta: LKiS

Muhibbin Syah, Psikologi dengan Pendekatan Baru, (Bandung: Remaja Rosdakarya, 2013). 